NASA/TM-2002-2:11567

AIAA-2002-2441

\title{
Evaluation of Far-Field Boundary Conditions for the Gust Response Problem
}

James R. Scott

Glenn Research Center, Cleveland, Ohio

Kevin L. Kreider and Jolın A. Heminger

University of Akron, Akron, Ohio 
The NASA STI Program Office ... in Profile

Since its founding, NASA has been dedicated to the advancement of aeronautics and space science. The NASA Scientific and Technical Information (STI) Program Office plays a key part in helping NASA maintain this important role.

The NASA STI Program Office is operated by Langley Research Center, the Lead Center for NASA's scientific and technical information. The NASA STI Program Office provides access to the NASA STI Database, the largest collection of aeronautical and space science STI in the world. The Program Office is also NASA's institutional mechanism for disseminating the results of its research and development activities. These results are published by NASA in the NASA STI Report Series, which includes the following report types:

- TECHNICAL PUBLICATION. Reports of completed research or a major significant phase of research that present the results of NASA programs and include extensive data or theoretical analysis. Includes compilations of significant scientific and technical data and information deemed to be of continuing reference value. NASA's counterpart of peerreviewed formal professional papers but has less stringent limitations on manuscript length and extent of graphic presentations.

- TECHNICAL MEMORANDUM. Scientific and technical findings that are preliminary or of specialized interest, e.g., quick release reports, working papers, and bibliographies that contain minimal annotation. Does not contain extensive analysis.

- CONTRACTOR REPORT. Scientific and technical findings by NASA-sponsored contractors and grantees.
- CONFERENCE PUBLICATION. Collected papers from scientific and technical conferences, symposia, seminars, or other meetings sponsored or cosponsored by NASA.

- SPECIAL PUBLICATION. Scientific, technical, or historical information from NASA programs, projects, and missions, often concerned with subjects having substantial public interest.

- TECHNICAL TRANSLATION. Englishlanguage translations of foreign scientific and technical material pertinent to NASA's mission.

Specialized services that complement the STI Program Office's diverse offerings include creating custom thesauri, building customized data bases, organizing and publishing research results ... even providing videos.

For more information about the NASA STI Program Office, see the following:

- Access the NASA STI Program Home Page at http://www.sti.nasa.gov

- E-mail your question via the Internet to help@sti.nasa.gov

- Fax your question to the NASA Access Help Desk at 301-621-0134

- Telephone the NASA Access Help Desk at 301-621-0390

- Write to: NASA Access Help Desk NASA Center for AeroSpace Information 7121 Standard Drive Hanover, MD 21076 


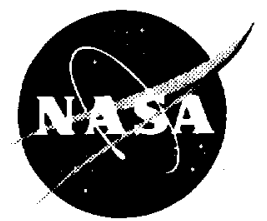

\section{Evaluation of Far-Field Boundary Conditions for the Gust Response Problem}

James R. Scott

Glenn Research Center, Cleveland, Ohio

Kevin L. Kreider and John A. Heminger

University of Akron, Akıon, Ohio

Prepared for the

Eighth Aeroacoustics Conference

cosponsored by the American Institute of Aeronautics and Astronautics

and the Confederation of European Aerospace Societies

Breckenridge, Colorado, June 17-19, 2002

National Aeronautics and

Space Administration

Glenn Research Center 
The Aerospace Propulsion and Power Program at NASA Glenn Research Center sponsored this work.

Available from

NASA Center for Aerospace Information 7121 Standard Drive

Hanover, MD 21076
National Technical Information Service 5285 Port Royal Road Springfield, VA 22100 


\title{
EVALUATION OF FAR-FIELD BOUNDARY CONDITIONS FOR THE GUST RESPONSE PROBLEM
}

\author{
James R. Scott* \\ National Aeronautics and Space Administration \\ Glenn Research Cener \\ Cleveland. Ohio 44135 \\ and \\ Kevin L. Kreider $\nmid$ and John A. Heminger + \\ The Eniversity of $\mathrm{Akion}$ \\ A kron. Olio +432:
}

\begin{abstract}
:
This paper presents a det iled study of four farfield boundary conditions use 1 in solving the single airfoil gust response problem The boundary conditions examined are the partial Sommerfeld radiation condition with only radial derivatives, the full Sommerfeld radiation conditio: with both radial and tangential derivatives, the Barliss-Turkel condition of order one, and the Hagstron:-Hariharan condition of order one. The main objectives of the study were to determine which far-field bundary condition was most accurate, which condition was least sensitive to changes in grid. and which con lition was best overall in terms of both accuracy and efficiency. Through a systematic study of the flat plate gust response problem, it was determined that th: Hagstrom-Hariharan condition was most accurate, the Bayliss-Turkel condition was least sensitive to rhanges in grid, and Bayliss-Turkel was best in te ms of both accuracy and efficiency.
\end{abstract}

\section{Introduction}

A fundamental problem in unsteady aerodynamics and aeroacoustics is he single airfoil gust response problem. This problem has a number of challenging features which make it an ideal model problem for CAA cocit validation. Among these features are mean flow distortion of the convected gust, vortex sheddirg in the wake, unsteady pressure on the airfoil surface, and acoustic waves which radiate to the far field. In the recent Third Computational Aeroacoustics Workshop on Benchmark Problen I $^{1}$, a series of benchmark solutions was presented for the gust problem

*Senior Research Scientist, Ac ,ustics Branch, Senior Member, AIAA

$\dagger$ Professor, Department of Tl coretical and Applied Mathematics

$\ddagger$ Associate Professor, Departn 'nt of Theoretical and Applied Mathematics using the GLST3D code ${ }^{2-4}$. Numerical solutions were also presented at the Workshop by Hixon ${ }^{1}$, et al and Kopriva'. of al. Additional solutions have been presented by Rasetarinera", et al and Wang." et al. While good agreement has been demonstrated for many of the comparisons, some cases have shown substantial discrepancies.

In an effort to improve the accuracy of the GUST3D solutions, a detailed study of four farfield boundary conditions was carried out. The boundary conditions examined were the partial Sommerfeld radiation condition with only radial derivatives. the full Sommerfeld radiation condition ${ }^{11}$ with both radial and tangential derivatives, the BaylissTurkel $^{i}$ condition of order one, and the HagstromHariharan $^{8}$ condition of order one. The main objectives of the study were to determine (i) which far-field boundary condition (FFBC) was most accurate, (ii) which FFBC was least sensitive to changes in grid. and (iii) which FFBC was best overall in terms of both accuracy and efficiency. To make these assessments, we constructed a matrix of test cases for the flat plate gust problem, and then repeatedly tested each FFBC on a large variety of grids for each case in the matrix. Using analytical solutions, we were then able to evaluate the relative accuracy of each boundary condition.

In the following section we review the mathematical formulation of the flat plate gust problem, and in Section III we summarize the numerical implementation. In Section IV we present and discuss the four FFBC's. Finally, in Section $V$ we describe the details of our numerical study and present the results.

\section{Mathematical Formulation}

\section{Governing Equation}

Consider an airfoil with chord length $c$ in a flow with uniform upstrean velocity $U_{\infty}$ in the $x_{1}$ direction. Let the fluid be an ideal gas which is inviscid and non-heat-conducting. Far upstream, let 
$\vec{u}_{x}=\vec{a} \epsilon^{i \vec{k} \cdot\left(\vec{x}-\vec{i} t \tau_{x} t\right)}$ denote a small amplitude gust, where $\vec{i}$ is a unit vector in the $x_{1}$ direction. Here $\vec{a}=\left(a_{1}, a_{2}, a_{3}\right)$, where the amplitude $|\vec{a}|$ satisfies $|\vec{a}|<<U_{\infty}, \vec{k}=\left(k_{1}, k_{2}, k_{3}\right)$ is the wave number vector, and $\vec{a}$ and $\vec{k}$ satisfy $\vec{a} \cdot \vec{k}=0$ to ensure that the continuity equation is satisfied.

We assume that the velocity field can be represented by

$$
\vec{U}(\vec{x}, t)=\vec{U}_{0}(\vec{x})+\vec{u}(\vec{x}, t)
$$

where $\vec{C}_{v}(\vec{r})$ is the steady potential velocity and $\vec{u}(\vec{x}, t)$ is the small, unsteady velocity: $\vec{u}(\vec{x}, t)$ may be decomposed ${ }^{9.10}$ into the sum of a known vortical component $\vec{u}^{(R)}$, and an unknown potential component $\vec{r}_{\phi}$, so that

$$
\vec{u}(\vec{r}, t)=\vec{u}^{(R)}-\vec{\Gamma} \phi .
$$

The vortical component $\vec{u}^{(R)}$ is essentially a func. tion of the mean flow Lagrangian coordinates and their spatial gradients. However, in the case of thin, uncambered airfoils at zero degrees incidence, the unsteady velocity decouples from the mean flow and $\vec{u}^{R)}$ reduces to $\vec{u}_{x}$.

The potential o satisfies the convective wave equation

$$
\frac{D_{0}}{D t}\left(\frac{1}{c_{0}^{2}} \frac{D_{0} \phi}{D t}\right)-\frac{1}{\rho_{0}} \vec{\Gamma} \cdot\left(\rho_{0} \vec{\Gamma} \phi\right)=\frac{1}{\rho_{0}} \vec{\Gamma} \cdot\left(\rho_{0} \vec{u}^{(R)}\right)
$$

where $\frac{D_{0}}{D t}$ is the convective derivative associated with the mean flow, and $c_{0}$ and $\rho_{0}$ are, respectively, the mean flow speed of sound and density. The unsteady pressure is given by

$$
p=-\rho_{0}(\vec{x}) \frac{D_{0} \phi}{D t} .
$$

For nonuniform mean flows, the coefficients of equation (2.3) and its source term depend strongly on the mean flow quantities. However, for a thin airfoil in a uniform parallel flow, the coefficients decouple from the mean flow and the source term vanishes. In this case the equation reduces to the constant coefficient convective wave equation

$$
\frac{1}{c_{0}^{2}} \frac{D_{0}^{2} \phi}{D t^{2}}-\Gamma^{2} \phi=0 .
$$

\section{Boundary Conditions}

At the airfoil surface the normal velocity component must vanish, so that $\left(\vec{u}^{(R)}+\vec{\nabla} \phi\right) \cdot \vec{n}=0$, or $\frac{\partial \phi}{\partial \eta}=-\vec{u}^{(R)} \cdot \vec{n}$. For a flat plate at zero degrees incidence, this reduces to

$$
\begin{gathered}
\frac{\partial \phi}{\partial x_{2}}=-a_{2} e^{i \vec{k} \cdot\left(\vec{x}-\vec{i} l_{\times} t\right)} \\
\frac{\partial \phi}{\partial x_{2}}=-a_{2} e^{i k_{1}\left(x_{1}-U_{\infty} l\right)+i k_{3} u_{s}}
\end{gathered}
$$

for $-\frac{r}{2} \leq x_{1} \leq \frac{c}{2}$, and $x_{2}=0$.

Across the wake the pressure is continuous, but $\phi$ has a discontinuity $\Delta \phi$ due to the unsteady circulation. Applying (2.4) on each side of the vortex sheet behind the airfoil leads to

$$
\frac{D_{0}}{D t}(\triangle \phi)=0
$$

for $x_{1}>\frac{c}{2}, x_{2}=0$.

Finally, $\phi$ must satisfy

$$
\vec{\Gamma} \phi \rightarrow 0 \text { as } \quad x_{1} \rightarrow-\infty \text {. }
$$

\section{Numerical Scheme}

Let lengths be normalized by $\frac{c}{2}$, time by $\frac{c}{2 U_{x}}$, $\phi$ by $\frac{c}{2}|\vec{a}|, \vec{a}$ by $|\vec{a}|$, and $U_{\alpha}$ and $c_{0}$ by $U_{\alpha}$. Then equation (2.5) and boundary conditions (2.7) - (2.9) become

$$
\left.\begin{array}{c}
M^{2} \frac{D^{2} \phi}{D t^{2}}-\Gamma^{2} \phi=0 \\
\frac{\partial \phi}{\partial x_{2}}=-a_{2} e^{i k_{1}\left(x_{1}-t\right)+i k_{3} x_{3}} \\
\text { for } \quad-1 \leq x_{1} \leq 1, \quad x_{2}=0
\end{array}\right\}
$$

where $\frac{D}{D t}=\frac{\partial}{\partial t}+\frac{\partial}{\partial x_{1}}$ and $M$ denotes the Mach number. The normalized wave number $k_{1}=\frac{p c}{2 U_{\alpha}}$, where $\nu$ is the angular frequency of the gust, is called the reduced frequency.

Introducing the change of variables

$x=x_{1}, \quad y=\beta x_{2}, \quad z=x_{3}$ where $\beta^{2}=1-M^{2}$

and

$$
\psi=\phi e^{i \frac{k_{1} M^{2}}{\beta^{2}} x} e^{i k_{1} t-i k_{3} z}
$$

equation (3.1) is transformed into the frequency domain and reduced to a Helmholt $z$ equation

$$
\frac{\partial^{2} \psi}{\partial x^{2}}+\frac{\partial^{2} \psi}{\partial y^{2}}+K^{2} \psi=0
$$


where

$$
K^{2}=\left(\frac{k_{1} M}{3^{2}}\right)^{2} \cdots\left(\frac{k_{3}}{\beta}\right)^{2} .
$$

Boundary conditions (3.2) - (3.4) become

$$
\begin{gathered}
\frac{\partial \psi}{\partial y}=-\frac{a_{2}}{\beta} e^{i k_{1} x / y^{2}} \quad \text { for } \quad-1 \leq x \leq 1 . \quad y=0 \\
\left(-\frac{i k_{1}}{\beta^{2}}+\frac{\partial}{\partial x}\right)(\Delta \psi)=0 \quad \text { f.r } \quad x>1 . \quad y=0 . \\
\overrightarrow{\Gamma \psi} \rightarrow 0 \text { as } \quad x \rightarrow-\infty .
\end{gathered}
$$

To solve (3.6) - (3.9) numarically; we introduce elliptic coordinates $(\eta . \xi)$, whe $\mathrm{e}$

$$
\begin{aligned}
& x=\cos (\pi \eta) \cosh (\pi \xi) \\
& y=\sin (\pi \eta) \sinh (\pi \xi) .
\end{aligned}
$$

Equation (3.6) then becomes

$$
\left.\begin{array}{c}
\frac{\partial^{2} \psi}{\partial \eta^{2}}+\frac{\partial^{2} \psi}{\partial \xi^{2}}+ \\
\pi^{2} K^{2}\left[\sin ^{2}(\pi \eta)-\sinh ^{2}(\pi, c)\right] \psi=0
\end{array}\right\}
$$

and the airfoil boundary cond tion (3.7) is

$$
\begin{array}{r}
\frac{\partial \psi}{\partial \xi}=-\frac{\pi a_{2}}{\beta} \sin (\pi \eta) e^{i k_{1} \cdot s(\pi \eta) / \alpha^{2}} \\
\quad \text { for } 0<\eta<1, \quad \xi=0 .
\end{array}
$$

The wake condition (3.8) can be integrated to obtain

$$
\Delta \psi=\Delta \psi_{1 . e .} e^{i k_{1}(x-1) / \beta^{2}}, \quad x>1, \quad y=0,
$$

where the subscript t.e. deno es the airfoil trailing edge. For a flat plate, $y$ is an odd function of $y$, so that for points above and belor the wake, $y=\frac{1}{2} \Delta \psi$ and (3.13) becomes

$$
\psi=\psi_{\text {t.e. }} e^{i k_{1}[\cosh (\pi \xi)-1] / h^{2}} \quad \eta=0, \quad \xi>0 .
$$

Since $\psi$ is odd, it is necsisary to solve (3.11) only in the upper half plane. ()ne therefore imposes the symmetry condition $\psi=0$ on the streamline ahead of the airfoil. This corusponds to the line $\eta$ $=1, \xi \geq 0$.

At the trailing edge, one rust impose the Kutta condition. This requires that $\frac{\eta \psi}{i \eta}=0$ at $\eta=0, \xi=$ 0.

Finally, we note that con lition (3.9) cannot be imposed at any finite distance from the airfoil without causing acoustic waves tı reflect off the outer grid boundary; thereby contaminating the numerical solution. Instead, one ml:t impose a radiation boundary condition which allows outgoing acoust ic waves to exit the computational domain. We discuss this in the next section.

Tun selection of an appropriate FFBC, the boundary value problem can be discretized in a straightforward manner using finite differences. The resulting matrix equation can then be solved using a spare matrix solver. See [4] for details.

\section{Radiation Boundary Conditions}

The simplest radiation boundary condition is the Sommerfeld condition ${ }^{11}$.

$$
\left(\frac{\partial}{\partial r}-i k\right) u=0
$$

where " satisfies the Helmholtz equation

$$
\frac{\partial^{2} u}{\partial x^{2}}+\frac{\partial^{2} u}{\partial y^{2}}-k^{2} u=0
$$

and the variable $r$ denotes polar distance. Although this condition is exact at infinity, it leads to spurious reflections wher imposed at a finite distance ${ }^{12}$.

Many authors have developed improved radiation conditions to reduce the spurious reflections. Our purpose here is not to review the various conditions that have been developed, but to examine the perfornance of two advanced radiation conditions versus the Sommerfeld condition.

We consider the Bayliss-Turkel ${ }^{7}$ (BT) and Hagstrom-Hariharan ${ }^{8}(\mathrm{HH})$ conditions of order one. These ran be expressed conveniently in operator notation. as follows. First, let

$$
B=i k-\frac{1}{2 r} \text {. }
$$

Then the BT condition is

$$
\left(\frac{\partial}{\partial r}-B\right) u=0
$$

Seconkl. let

$$
H=i k-\frac{1}{r}
$$

and

$$
J=-\left(i k-\frac{1}{2 r}\right) H+\frac{1}{8 r^{2}} .
$$

Then the HH condition is

$$
\left(J+H \frac{\partial}{\partial r}+\frac{1}{2 r^{2}} \frac{\partial^{2}}{\partial \theta^{2}}\right) u=0
$$

where $\theta$ denotes the polar angle.

Cinditions (4.1), (4.4), and (4.6) are accurate t. $O\left(r^{-3 / 2}\right), O\left(r^{-5 / 2}\right)$, and $O\left(r^{-i / 2}\right)$, respect- 
ively ${ }^{78.14}$. It must be noted, however, that these conditions were derived for circular boundaries. The elliptic coordinate transformation (3.10) provides an outer boundary which is nearly circular for most. problems. However, there will be a loss of accuracy as the outer boundary deviates from a circle.

Fach of the above conditions can be applied to the transformed potential $\%$, since? satisfies the Helmholtz equation. However, it has been previously obscrved that this does not lead to accurate far-field pressure calculations ${ }^{4,13}$. A far superior approach is to apply the radiation condition to the pressure $p$, which also satisfies equation (3.6). This leads to an additional operator acting on $\psi$ in the far-field boundary condition. From equation (2.4), this operator is

$$
\left(\frac{\partial}{\partial r}-A\right)
$$

where

$$
A=\frac{i k_{1}}{\beta^{2}}
$$

We may therefore identify the variable $u$ in (4.1) (4.6) with the pressure $p$ and write (leaving out the minus sign)

$$
u=\left(\frac{\partial}{\partial x}-A\right) \psi
$$

The Sommerfeld, BT, and HH pressure radiation conditions are then

$$
\begin{gathered}
\left(\frac{\partial}{\partial r}-i K\right)\left(\frac{\partial}{\partial x}-A\right) \psi=0 \\
\left(\frac{\partial}{\partial r}-B\right)\left(\frac{\partial}{\partial x}-A\right) \psi=0 \\
\left(J+H \frac{\partial}{\partial r}+\frac{1}{2 r^{2}} \frac{\partial^{2}}{\partial \theta^{2}}\right)\left(\frac{\partial}{\partial r}-A\right) \psi=0
\end{gathered}
$$

respectively; where the frequency $k$ in $(4.1)-(4.6)$ is now identified with $K$ as defined in (3.6b).

\section{Numerical Study}

The main objectives of our study were to determine which radiation condition was most accurate. which was least sensitive to changes in grid, and which was best overall in terms of both accuracy and efficiency. We also wanted to compare the partial Sommerfeld (PS) condition, which uses only radial derivatives, with the full Sommerfeld (FS) condition, which retains all derivatives.

To test the boundary conditions, we constructed a test matrix of problems in which the Mach number $M$ ranged from 0.1 to 0.5 to 0.8 . with reduced frequency values $k_{1}$ of $0.1,0 . \overline{5}, 1.0,2.0$. and 3.0 at each Mach number. For each case in the natrix we solved the gust problem on a set of 15 different grids. The grids varied in their spacing in the tangential direction and also in the location of the outer grid boundary. The spacing in the radial direction was kept fixed at 24 points per wavelength. Each grid was designed to provide an accurate calculation so that differences in accuracy that appeared would be due to the given FFBC. Two parameters in the GLST3D code were used to vary the grids. The parameter "neta", which specifies the number of $\eta$ grid points. was used to vary the spacing in the tangential direction. The parameter "nwaves", which specifies the number of wavelengths to be used in

\begin{tabular}{|c|c|c|}
\hline Grid No. & neta & nwaves \\
\hline 1 & 41 & 5.0 \\
\hline 2 & 41 & 5.5 \\
\hline 3 & 41 & 6.0 \\
\hline 4 & 41 & 6.5 \\
\hline 5 & 41 & 7.0 \\
\hline 6 & 46 & 5.0 \\
\hline 7 & 46 & 5.5 \\
\hline 8 & 46 & 6.0 \\
\hline 9 & 46 & 6.5 \\
\hline 10 & 46 & 7.0 \\
\hline 11 & 51 & 5.0 \\
\hline 12 & 51 & 5.5 \\
\hline 13 & 51 & 6.0 \\
\hline 14 & 51 & 6.5 \\
\hline 15 & 51 & 7.0 \\
\hline
\end{tabular}
the wake boundary condition, was used to vary the location of the outer grid boundary. Tables I and II summarize the grid configurations that were used.

$\begin{array}{ccc}\text { Grid Vo. } & \text { neta } & \text { nwaves } \\ 1 & & 3.0 \\ 2 & 31 & 3.5 \\ 3 & 31 & 4.0 \\ 4 & 31 & 4.5 \\ 5 & 31 & 5.0 \\ 6 & 36 & 3.0 \\ 7 & 36 & 3.5 \\ 8 & 36 & 4.0 \\ 9 & 36 & 4.5 \\ 10 & 36 & 5.0 \\ 11 & 41 & 3.0 \\ 12 & 41 & 3.5 \\ 13 & 41 & 4.0 \\ 14 & 41 & 4.5 \\ 15 & 41 & 5.0\end{array}$

Table I Grid Parameters for $k_{1}=0.1,0.5,1.0$

Table II Grid Parameters for $k_{1}=2.0,3.0$ 
To assess accuracr, we compared numenical and exact pressure values on a semicircle of radius two chord lengths centered at the airfoil center, as shown in Figure 1. Figures 2 and 3 thow comparisons between numerical and exact re-ults from typical calculations.

To quantify the error, we used two error norms - absolute $I_{x}$ and relative $L \because$. The absolute $L_{x}$ norm was calculated by

$$
\max _{n}\left|P_{(\text {omp }}^{n}-P_{\mathrm{ex}}^{n}\right|, \quad n=0,1, \ldots 360
$$

where the semicircle was discretized by 361 uniformly spaced points and $P_{c o m}^{n}$, and $P_{e x}^{n}$ are the computed and exact pressure at point $n$. respectively. The relative $L_{2}$ error was calcilated by

$$
\sqrt{\sum_{n=0}^{360}\left(P_{\mathrm{comp}}^{n}-P_{\mathrm{ex}}^{n}\right)^{2}} ; \sqrt{\sum_{n=0}^{360}\left(P_{\mathrm{e}}^{n}\right)^{2}} .
$$

Using the above error noms, we were able to compare the accuracy of one liFBC versus another. We illustrate this in Figures 1-9. In Figure 4. for example, we show the absolute $L_{\infty}$ error for all four boundary conditions for the case $M=0.1, k_{1}=1.0$. on all 15 grids. From the plet one can readily see which FFBC was most accurate and which one was least sensitive to the change in grid. At the top of the figure we show the maxil sum $L_{\infty}$ error, mean $L_{\infty}$ error, and standard deviation for each of the four boundary conditions. It is seen that for this particular case, the Hagstron -Hariharan condition was superior to the other three conditions in all three. categories. On the other hard, the Bayliss-Turkel condition had the smallest mix and mean error in Figures 5 and 8 , and the smallest standard deviation in Figure 9.

Plots analogous to those in Figures $4-9$ were made for every case in the text matrix, however for brevity they are omitted here. This made it possible to do a complete evaluation of the four boundary conditions. Tables III and IV summarize which FFBC was best in the categories of smallest max error, smallest mean error, and smallest standard deviation for all the cases in the est matrix. It is clear that the Bayliss-Turkel and Hagstrom-Hariharan conditions performed the best. How much better they performed is shown in Figures $10-15$. In Figure 10 , for example, we consider the $L_{\infty}$ max error The figure shows the ratio of max error to the partial Sommerfeld max error for the other three boundary conditions. The ratio is show: for each case in the test matrix. An error ratio less than one indicates an improvement over the part al Sommerfeld condition, which is the simplest $o^{\circ}$ the four conditions.

\begin{tabular}{|c|c|c|c|c|}
\hline$M$ & $k_{1}$ & Max Frron & Mean Frror & Stand Dey \\
\hline$\overline{0.1}$ & 0.1 & $\mathrm{HH}$ & $\mathrm{HH}$ & HH \\
\hline 0.1 & 0.5 & BT & $\mathrm{HH}$ & BT \\
\hline 0.1 & 1.0 & $\mathrm{HH}$ & $\mathrm{HH}$ & $\mathrm{HH}$ \\
\hline 0.1 & 2.0 & $\mathrm{HH}$ & $\mathrm{HH}$ & $\mathrm{HH}$ \\
\hline 0.1 & 3.0 & $\mathrm{HH}$ & $\mathrm{HH}$ & $\mathrm{HH}$ \\
\hline 0.5 & 0.1 & BT & BT & $\mathrm{HH}$ \\
\hline 0.5 & 0.5 & BT & BT & BT \\
\hline 0.5 & 1.0 & BT & BT & $\mathrm{HH}$ \\
\hline 0.5 & 2.0 & $\mathrm{HH}$ & $\mathrm{HH}$ & BT \\
\hline 0.5 & 3.0 & $\mathrm{HH}$ & $\mathrm{HH}$ & BT \\
\hline 0.8 & 0.1 & BT & BT & BT \\
\hline 0.8 & $0 . \bar{J}$ & BT & $\mathrm{BT}$ & $\mathrm{HH}$ \\
\hline 0.8 & 1.0 & $\mathrm{HH}$ & $\mathrm{HH}$ & BT \\
\hline 0.8 & 2.0 & $\mathrm{HH}$ & PS & BT \\
\hline 0.8 & 3.0 & PS & PS & $\mathrm{BT}$ \\
\hline
\end{tabular}
An inspection of Figures $10-15$ indicates that the
Table III Best Far-Field Boundary Condition

\begin{tabular}{|c|c|c|c|c|}
\hline$\underline{M}$ & $\underline{k_{1}}$ & Max Error & Mean Frror & Stand Dev \\
\hline 0.1 & 0.1 & BT & BT & BT \\
\hline 0.1 & 0.5 & $\mathrm{BT}$ & BT & BT \\
\hline 0.1 & 1.0 & $\mathrm{HH}$ & $\mathrm{HH}$ & $\mathrm{HH}$ \\
\hline 0.1 & 2.0 & $\mathrm{HH}$ & $\mathrm{HH}$ & $\mathrm{HH}$ \\
\hline 0.1 & 3.0 & $\mathrm{HH}$ & $\mathrm{HH}$ & $\mathrm{HH}$ \\
\hline 0.5 & 0.1 & BT & BT & BT \\
\hline 0.5 & 0.5 & BT & $\mathrm{BT}$ & $\mathrm{HH}$ \\
\hline 0.5 & 1.0 & BT & $\mathrm{BT}$ & $\mathrm{HH}$ \\
\hline 0.5 & 2.0 & $\mathrm{HH}$ & $\mathrm{HH}$ & BT \\
\hline 0.5 & 3.0 & $\mathrm{HH}$ & $\mathrm{HH}$ & BT \\
\hline 0.8 & 0.1 & $\mathrm{BT}$ & BT & BT \\
\hline 0.8 & 0.5 & $\mathrm{HH}$ & BT & $\mathrm{HH}$ \\
\hline 0.8 & 1.0 & $\mathrm{HH}$ & $\mathrm{HH}$ & BT \\
\hline 0.8 & 2.0 & PS & PS & PS \\
\hline 0.8 & 3.0 & PS & PS & FS \\
\hline
\end{tabular}
Based on Absolulte $L_{\infty}$ Frror

Tatble IV Best Far-Field Boundary Condition Based on Relative $L_{2}$ Error

Bayliss-Turkel and Hagstrom-Hariharan conditions performed significantly better than the partial Sommerfeld condition both in terms of accuracy and in terms of consistency of solution (i.e., insensitivity to change in grid). On the other hand. the results also show that the partial Sommerfeld condition performed as well as or better than the full Sommerfeld condition.

To determine which FFBC was most accurate and which was least sensitive to changes in grid, we use the results shown in Tables III and IV. One finds that in the categories of lowest max error and lowest mean urror. the Hagstrom-Hariharan condition was the best 29 out of 60 times, while the Bayliss-Turkel condition was best 24 times. We therefore conclude that the Hagstrom-Hariharan condition was 
the most accurate overall. On the other hand. in the? category of smallest standard deviation, one finds that the Bayliss-Turkel condition was the best 15 out of 30 times, while the Hagstrom-Hariharan condition was best 13 times. We therefore conclude that the Bayliss-Turkel condition was the least sensitive overall to a change in grid.

In terms of computational efficiency, partial Sommerfeld was the most efficient of the four boundary conditions. This is due to its smaller discretization stencil, resulting in a sparser matrix than that of the other boundary conditions. The full Sommerfeld and Bayliss-Turkel conditions required an increase in CPL time over partial Sommerfeld of about $3 \%$. However, they required an increase in computer storage of about $52 \%$. Similarly, the HagstromHariharan condition required an increase in CPL time over partial Sommerfeld of about $10 \%$, while requiring an increase in computer storage of about $102 \%$. Clearly, the biggest cost associated with the three more advanced boundary conditions was the substantial increase in required storage. Since the Bayliss-Turkel condition was only slightly less accurate than the Hagstrom-Hariharan condition while providing the most grid independent solution at a cost of only a $52 \%$ increase in storage, we conclude that the Bayliss-Turkel condition was the best overall boundary condition.

\section{Summary}

A detailed study of the accuracy and efficiency of the partial Sommerfeld, full Sommerfeld, order-1 Bayliss-Turkel, and order-1 Hagstrom-Hariharan radiation boundary conditions was carried out. Each boundary condition was tested on a matrix of problems with three different Mach numbers and five different reduced frequencies. It was determined that Hagstrom-Hariharan was most accurate overall, Bayliss-Turkel was least sensitive to changes in grid, and Bayliss-Turkel was best overall in terms of both accuracy and efficiency. In addition, it was determined that full Sommerfeld did not yield any improvements over partial Sommerfeld. Finally, it was determined that for far-field pressure calculations, both Bayliss-Turkel and Hagstrom-Hariharan are sufficiently superior to Sommerfeld that they are well worth the additional cost of implementation.

\section{References}

1. Third Computational Aeroacoustics (CAA) Workshop on Benchmark Problems, Proceedings of a conference held at and sponsored by Ohio Aerospace Institute, Cleveland, Ohio, Nov. 8-10, 1999. NASA/CP-2000-209790.
2. Scott, J.R. and Atassi, H.M., "Numerical Solutions of the Linearized Euler Fquations for Unsteady Vortical Flows Around Lifting Airfoils," AIA Paper 90-0694, January, 1990.

3. Scot, J.R. and Atassi, H.M., "High Frequency Gust Interaction with Single Loaded Airfoils in Subsonic Flows" Proceedings of the Sixth International Symposium on Unsteady Aerodynamics, Aeroacoustics and Aeroelasticity of Turbomachines and Propellers, University of Notre Dame, H.M. Atassi, ed., (Springer-Verlag. New York, 1991), 743-764.

4. Scott, J.R. and Atassi. H.M., "A FiniteDifference, Frequency-Domain Numerical Scheme for the Solution of the Gust Response Problem," J. Comp. Phys. 119, 75-93 (1995).

5. Rasetarinera, P., Kopriva, D.A., and Hussaini, M.Y., "Discontinuous Spectral Element Solution of Acoustic Radiation from Thin Airfoils." AIA A Journal, 39, No. 11, 2070-2075, (2001).

6. Wang, X.Y., Chang, S.C., Himansu, A., and Jorgenson, P., "Gust Acoustic Response of a Single Airfoil Lsing the Space-Time CE/SF Method," AIAA Paper 2002-0801, January, 2002.

7. Bayliss, A. and Turkel, E., "Radiation boundary conditions for wave-like equations," Comm. Pure Appl. Math. 33, 707-725 (1980).

8. Hagstrom, T. and Hariharan, S.I., "A formulation of asymptotic and exact boundary conditions using local operators," Appl. Numer. Math. 27, 403-416 (1998).

9. Goldstein, M.E., "Unsteady vortical and entropic distortions of potential flows round arbitrary obstacles," J. Fluid Mech. 89, 433-468. (1978).

10. Atassi. H.M. and Grzedzinski. J.. "Unsteady disturbances of streaming motions around bodies," J. Fluid Mech. 209, 385-403, (1989).

11. Sommerfeld, A., Partial Differential Equations in Physics, Academic Press, New York, 1964.

12. Keller, J.B. and Givoli, D.. "Exact Nonreflecting Boundary Conditions," J. Comp. Phys. 82, 172-192 (1989).

13. Scott, J.R. and Atassi, H.M., "Numerical Solution of Periodic Vortical Flows About a Thin Airfoil," NASA TM 101998, June, 1989.

14. Bayliss, A., Gunzburger, M., and Turkel, F., "Boundary Conditions for the Numerical Solution of Elliptic Equations in Exterior Regions,"SIAM. J. Appl. Math. 42, No. 2, 430-451 (1982). 


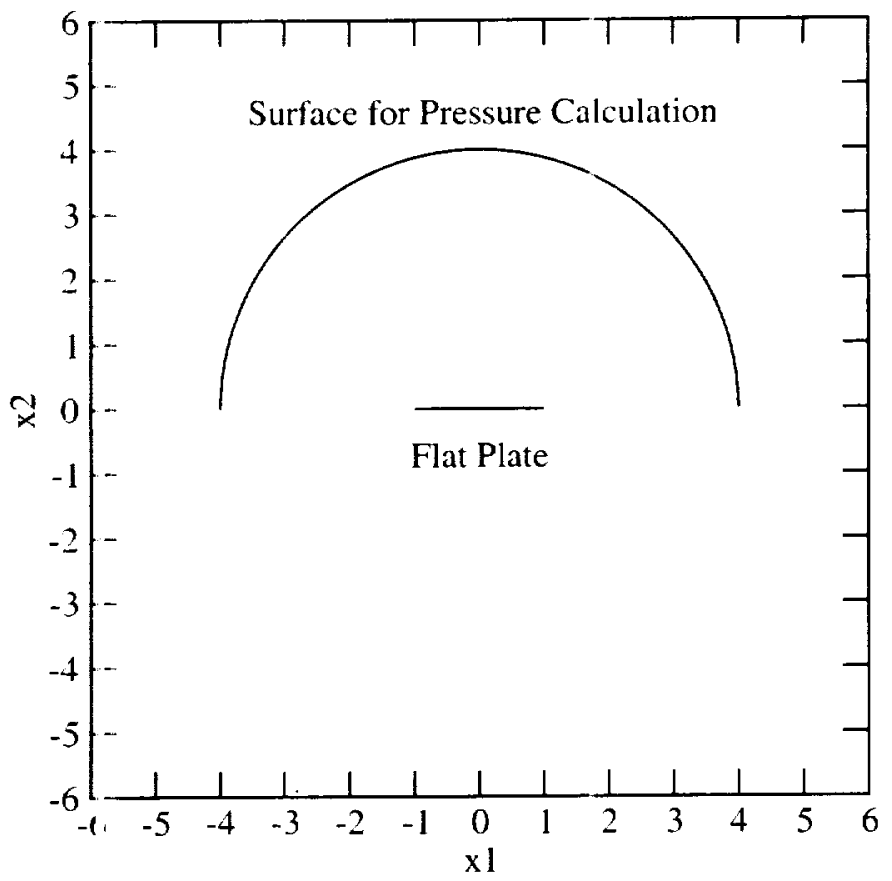

Figue 1 Semicircle of radius two chord lengths for far-field pressure calculation

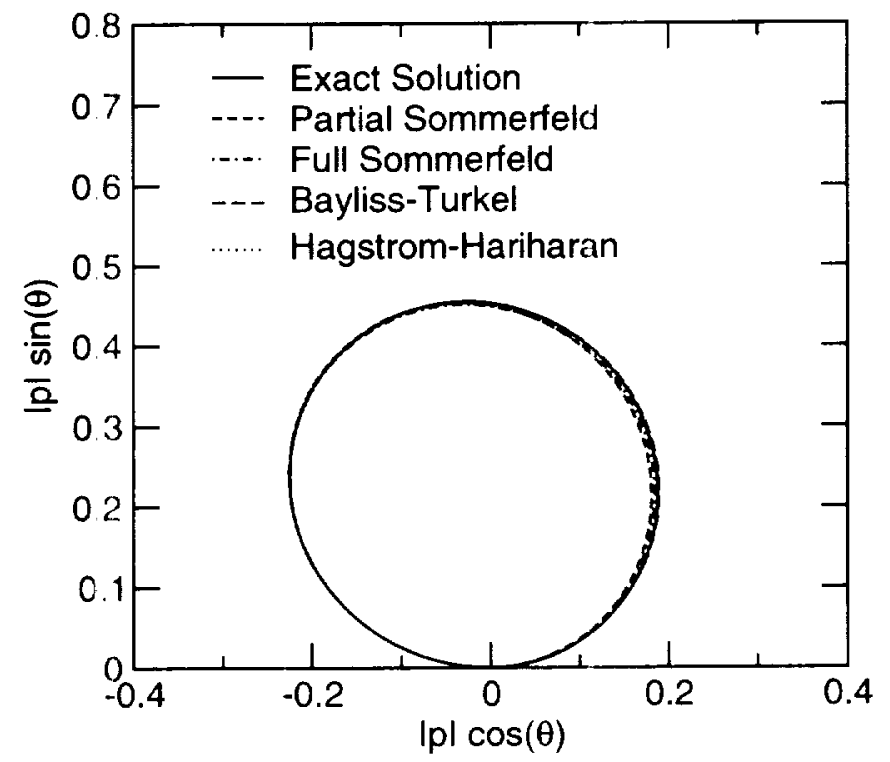

Figlire 2 Comparison of far-field pressure on semicircle of radius two chord lengths. $\mathrm{M}=0.5, \mathrm{kl}=1.0$, flat plate in a transverse gust. 


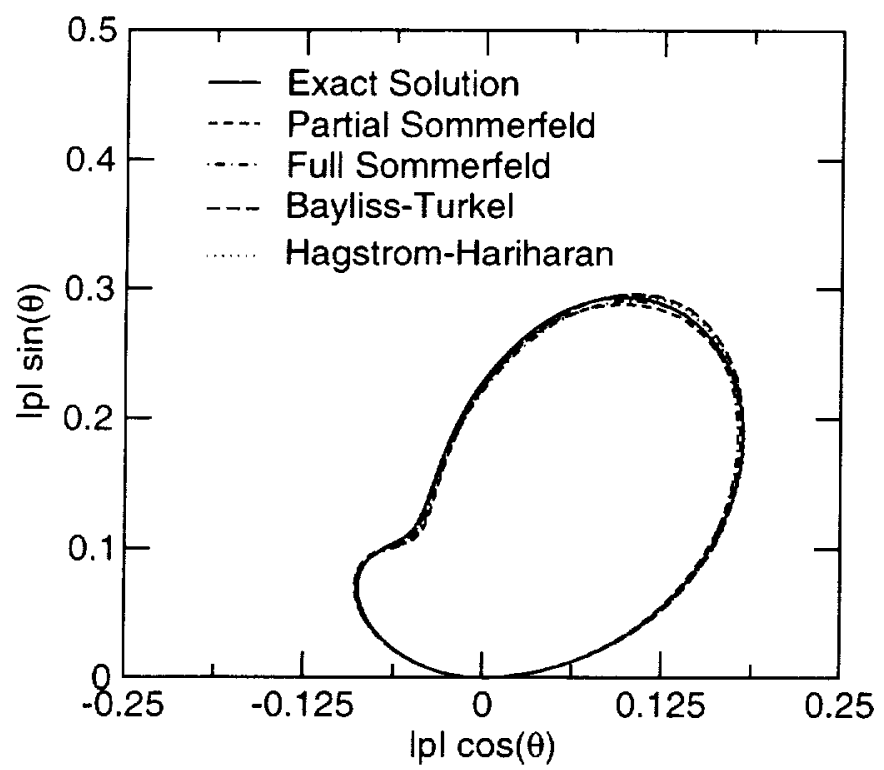

Figure 3 Comparison of far-field pressure on semicircle of radius two chord lengths. $M=0.5, \mathrm{kl}=3.0$, flat plate in a transverse gust.

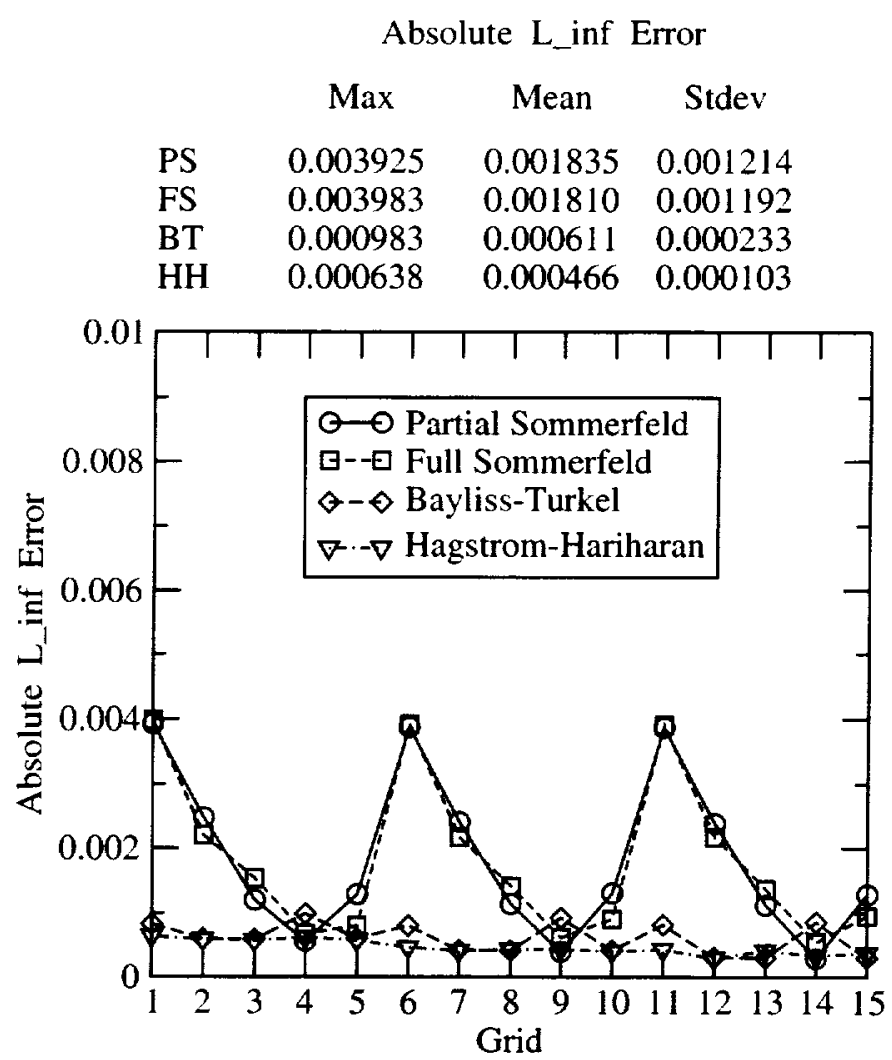

Figure 4 Absolute L_inf error for all four FFBC's on 15 different grids for the case $\mathrm{M}=0.1, \mathrm{kl}=1.0$ 
Absolute L_inf Error

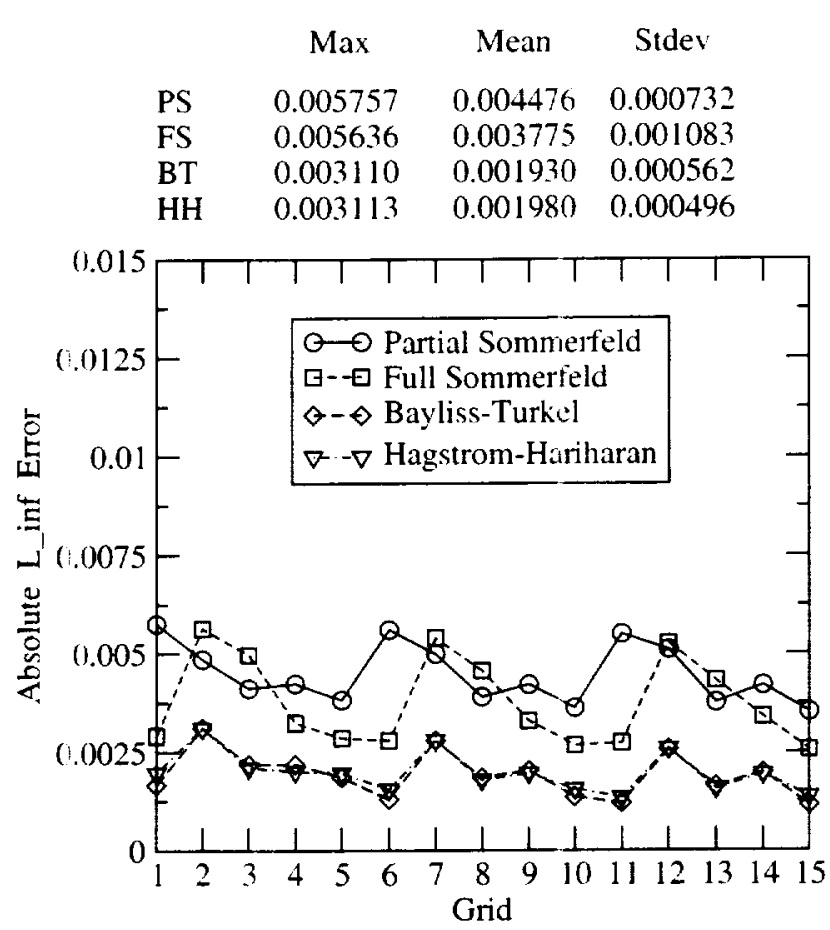

Figure 5 Absolute L_inf error for all four FFBC's on 15 different grids for the case $\mathrm{M}=0.5, \mathrm{kl}=1.0$

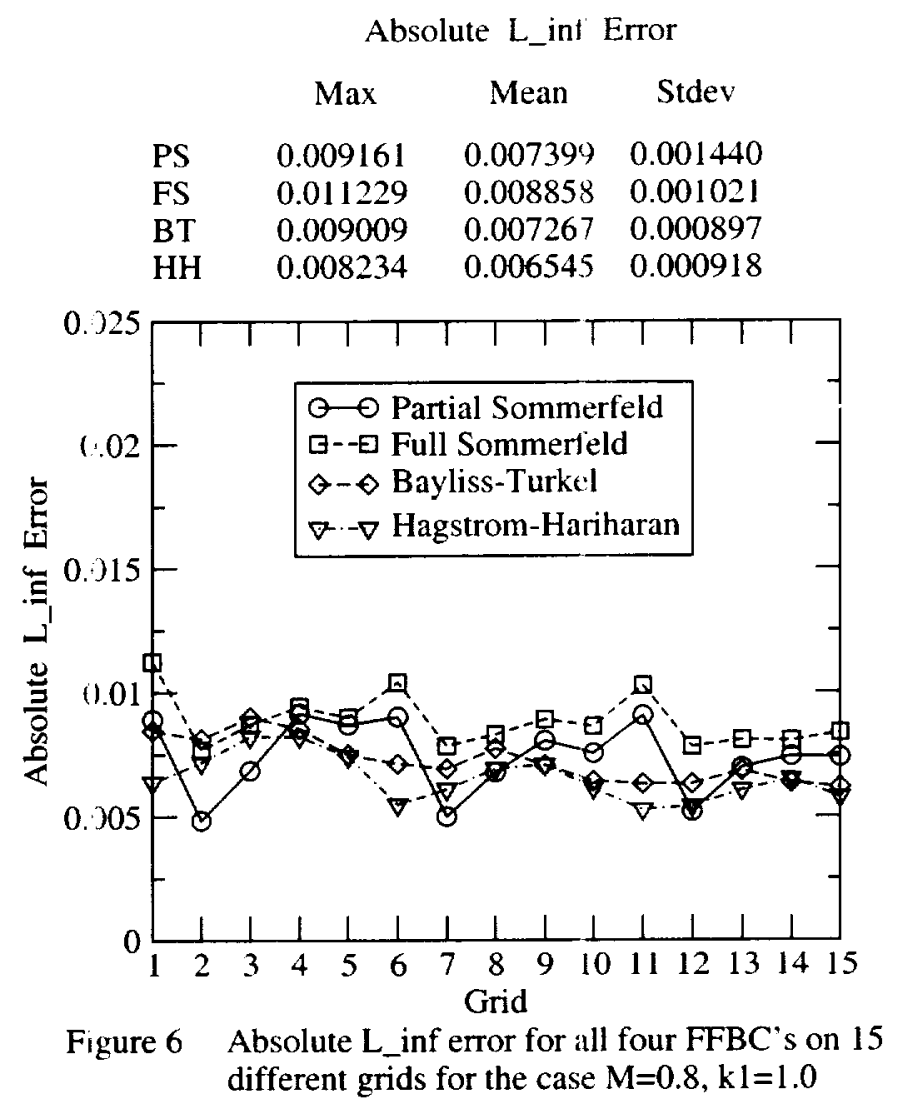


Relative L2 Error

$\begin{array}{lccc} & \text { Max } & \text { Mean } & \text { Stdev } \\ \text { PS } & 0.03574 & 0.01603 & 0.01159 \\ \text { FS } & 0.03591 & 0.01595 & 0.01115 \\ \text { BT } & 0.00759 & 0.00417 & 0.00261 \\ \text { HH } & 0.00366 & 0.00265 & 0.00068\end{array}$

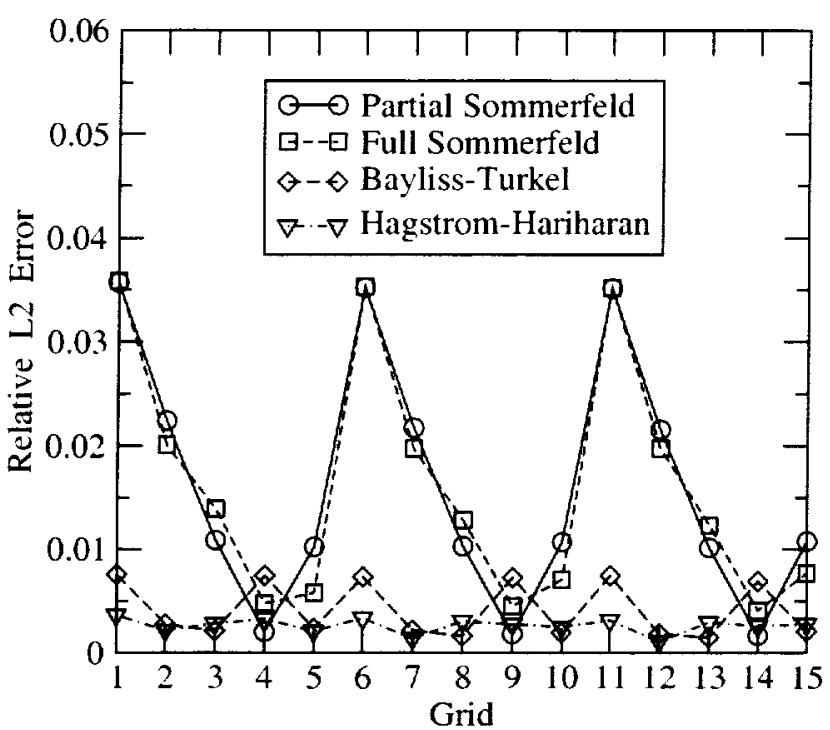

Figure 7 Relative L_2 error for all four FFBC's on 15 different grids for the case $M=0.1, \mathrm{k} 1=1.0$

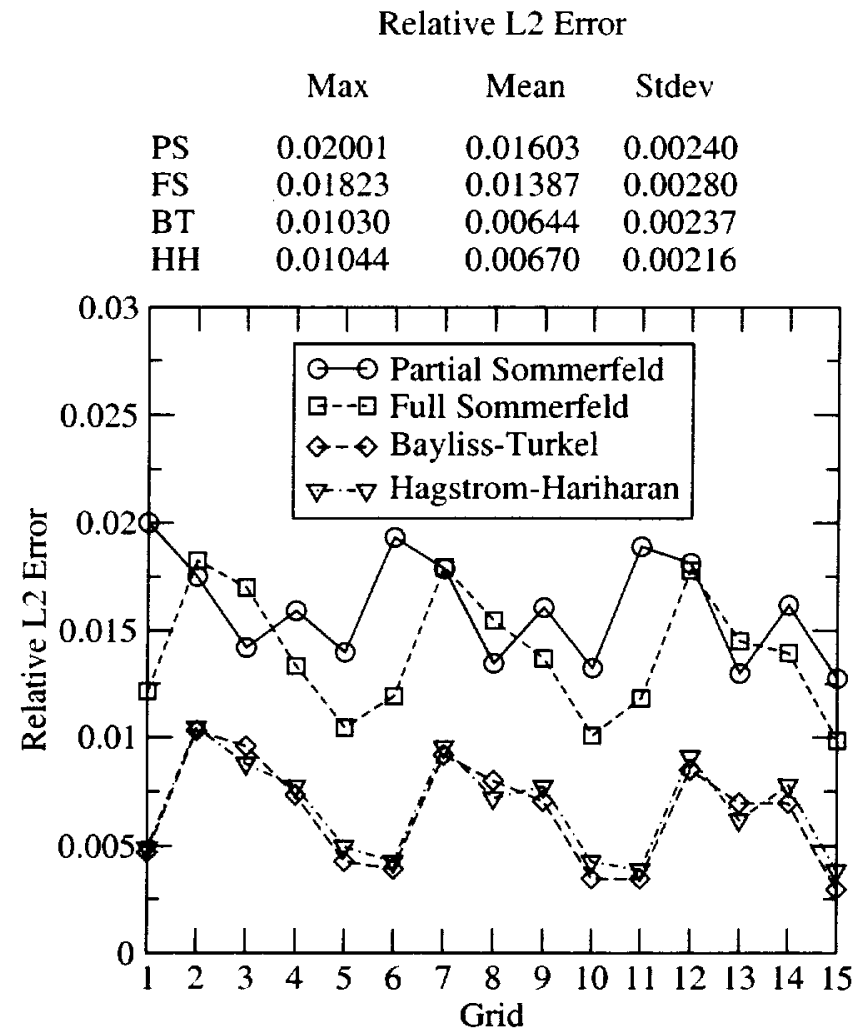

Figure 8 Relative L_2 error for all four FFBC's on 15 different grids for the case $\mathrm{M}=0.5, \mathrm{kl}=1.0$ 


\begin{tabular}{lccc} 
& \multicolumn{3}{c}{ Relative L2 Eiror } \\
& Max & Mean & Stdev \\
& & & \\
PS & 0.02932 & 0.02208 & 0.00444 \\
FS & 0.03014 & 0.02416 & 0.00378 \\
BT & 0.02526 & 0.02054 & 0.00245 \\
HH & 0.02521 & 0.01885 & 0.00346
\end{tabular}

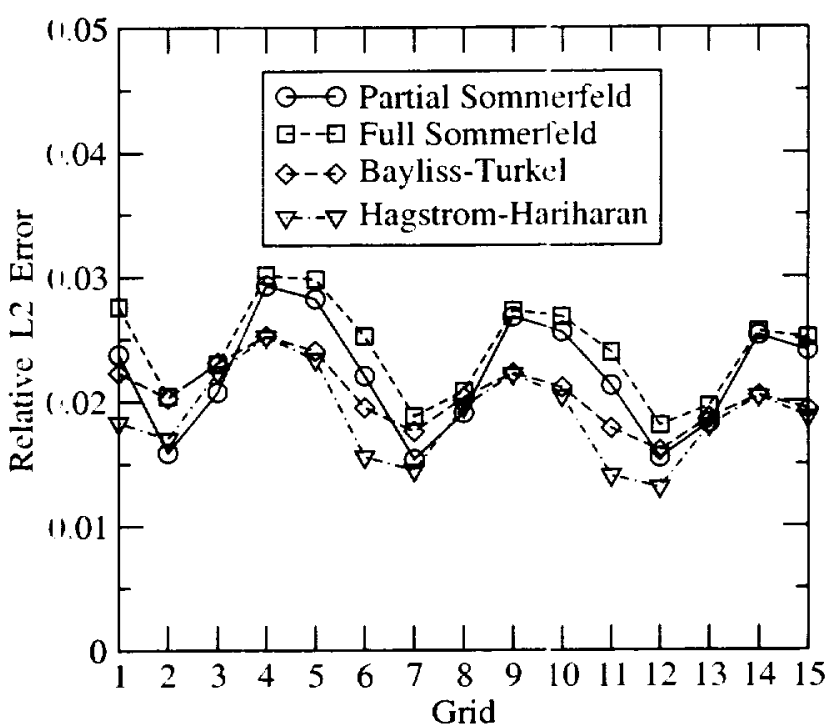

F gure 9 Relative $\mathrm{L}_{-} 2$ error for all four FFBC's on 15 different grids for the case $\mathrm{M}=0.8, \mathrm{kl}=1.0$

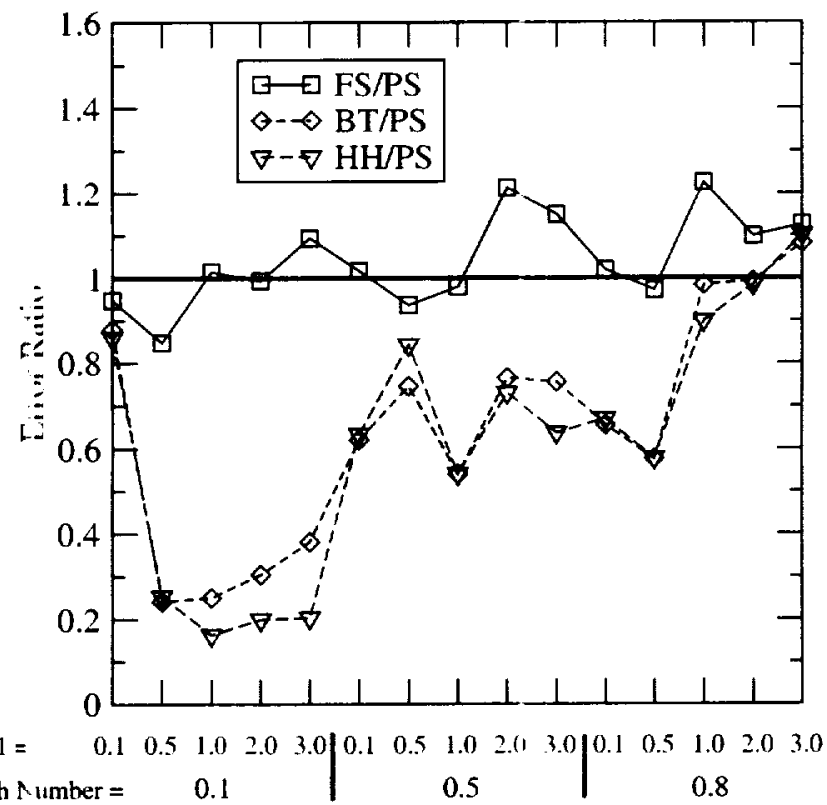

Figure 10 Ratio of L_inf max error to partial Sommerfeld L_inf max error for all caves in the test matrix 


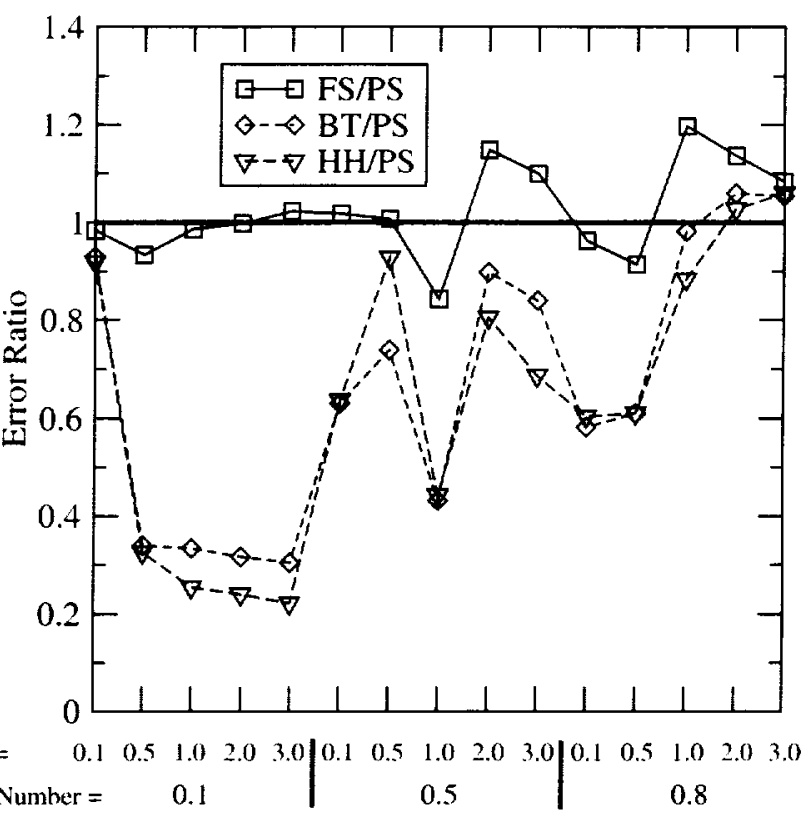

Figure 11 Ratio of L_inf mean error to partial Sommerfeld L_inf mean error for all cases in the test matrix

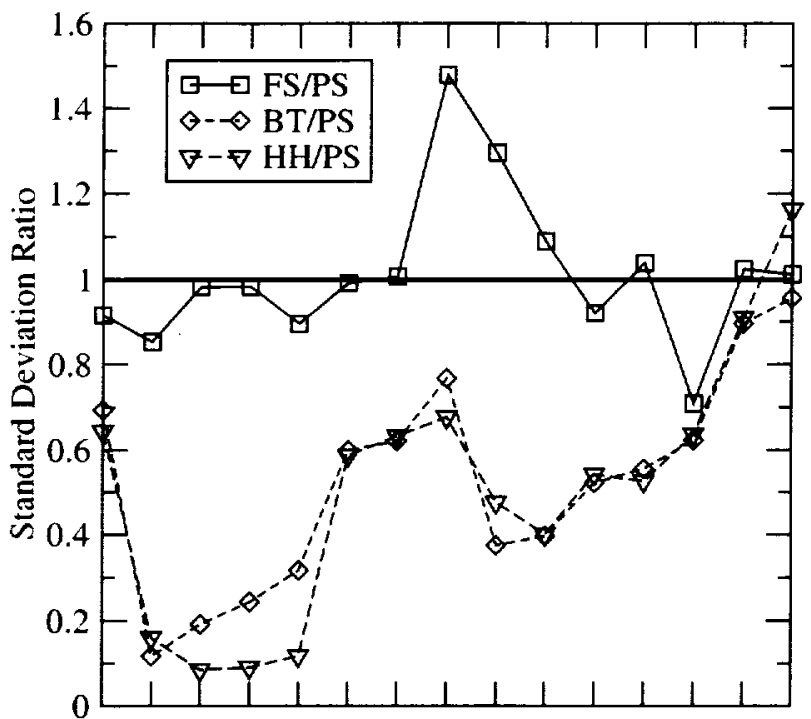
Mach Number $=$ 0.1 0.8

Figure 12 Ratio of $L_{-}$inf stand. dev. to partial Sommerfeld L_inf stand. dev. for all cases in the test matrix 


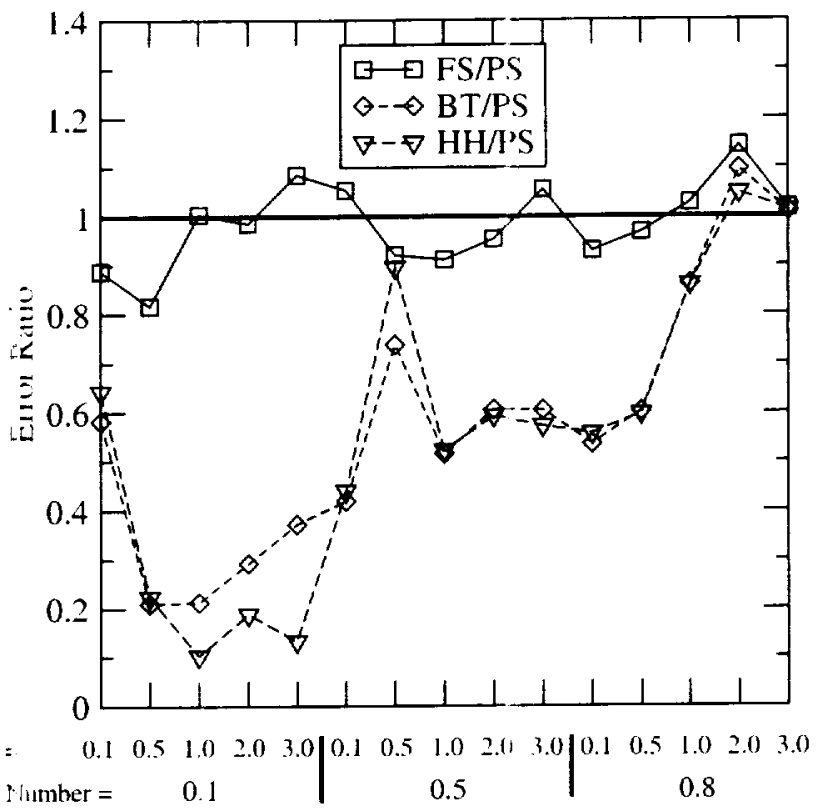

Figure 13 Ratio of L 2 max error to partial Sommerfeld L_2 max error for all case's in the test matrix

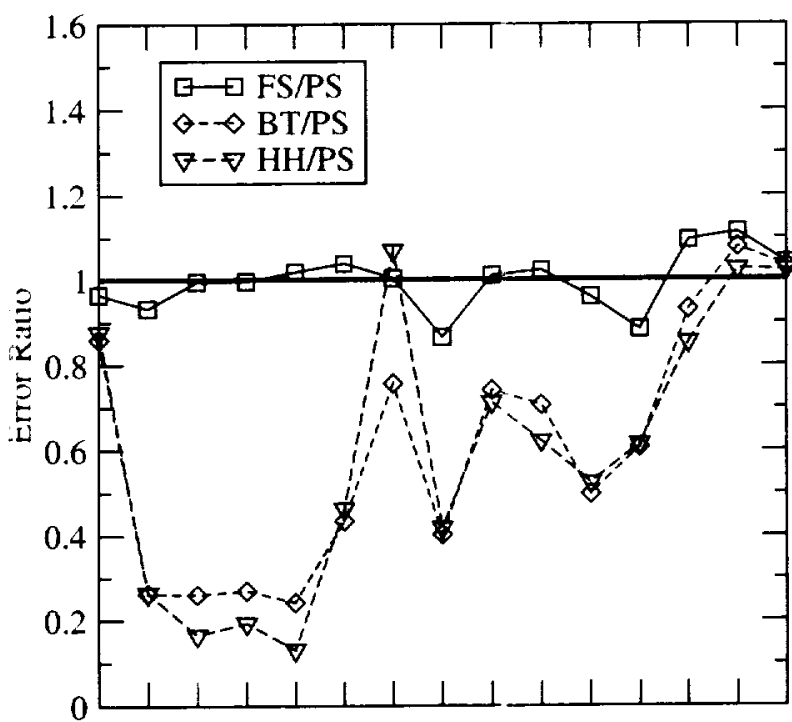

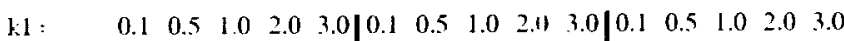
Mach vumber $=0.1 \quad 0.5 \quad 0.8$

Fig ure 14 Ratio of L_2 mean error to partial Sommerfeld L_2 mean error for all cases in the test matrix 


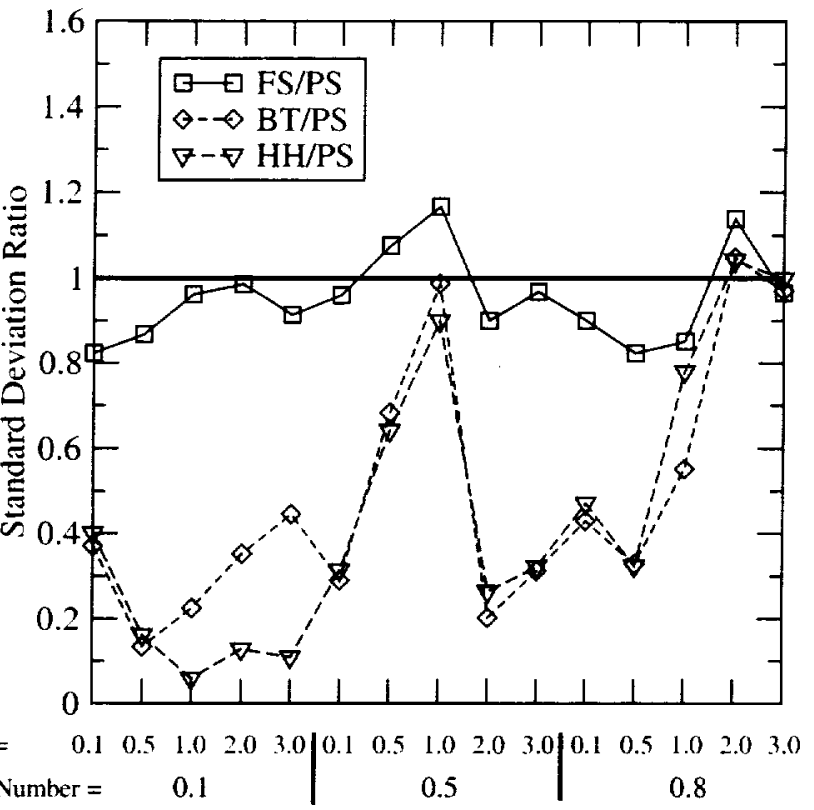

Figure 15 Ratio of $\mathrm{L} \_2$ stand. dev, to partial Sommerfeld L_2 stand. dev. for all cases in the test matrix 
Public reporting burden for this collection of information is estimated to average 1 hour per response, including the time for reviewing instructions, searching existing data sources. gathering and maintaining the data needed, and completing and reviewing the collection of information. Send comments regarding this burden estimate or any other aspect of this collection of information, including suggestions for reducing this burden, to Washington Headquarters Services, Directorate tor Information Operations and Reports, 1215 Jefferson Davis Highway. Suite 1204, Artington, VA 22202-4302. and to the Office of Management and Budget, Paperwork Reduction Project (0704-0188). Washington, DC 20503.

\begin{tabular}{l|l|l|} 
1. AGENCY USE ONLY (Leave blank) & 2. REPORT DATE & 3EPORT TYPE AND DATES COVERED
\end{tabular}

4. TITLE AND SUBTITLE June 2002

Technical Memorandum

Evaluation of Far-Field Boundary Conditions for the Gust Response Problem

6. AUTHOR(S)

WU-708-90-33-00

James R. Scott, Kevin L. Kreider, and John A. Heminger

7. PERFORMING ORGANIZATION NAME(S) AND ADDRESS(ES)

National Aeronautics and Space Administration

John H. Glenn Research Center at Lewis Field

Cleveland, Ohio 44135-3191

8. PERFORMING ORGANIZATION REPORT NUMBER

$$
E-13351
$$

\section{SPONSORING/MONITORING AGENCY NAME(S) AND ADDRESS(ES)}

National Aeronautics and Space Administration

Washington, DC 20546-0001

10. SPONSORING/MONITORING AGENCY REPORT NUMBER

NASA TM-2002-211567

AIAA-2002-2441

11. SUPPLEMENTARY NOTES

Prepared for the Eighth Aeroacoustics Conference cosponsored by the American Institute of Aeronautics and Astronautics and the Confederation of European Aerospace Societies, Breckenridge. Colorado, June 17-19, 2002. James R. Scott, NASA Glenn Research Center; Kevin L. Kreider and John A. Heminger, University of Akron, Akron, Ohio 44325. Responsible person. James R. Scott, organization code 5940, 216-433-5863.

12a. DISTRIBUTION/AVAILABILITY STATEMENT

12b. DISTRIBUTION CODE

Unclassified - Unlimited

Subject Category: 64

Distribution: Nonstandard

Available electronically at http://gltrs.grc.nasa.gov/GLTRS

This publication is available from the NASA Center for AeroSpace Information. 301-621-0390.

13. ABSTRACT (Maximum 200 words)

This paper presents a detailed study of four far-field boundary conditions used in solving the single airfoil gust response problem. The boundary conditions examined are the partial Sommerfeld radiation condition with only radial derivatives, the full Sommerfeld radiation condition with both radial and tangential derivatives, the Bayliss-Turkel condition of order one, and the Hagstrom-Hariharan condition of order one. The main objectives of the study were to determine which far-field boundary condition was most accurate, which condition was least sensitive to changes in grid, and which condition was best overall in terms of both accuracy and efficiency. Through a systematic study of the flat plate gust response problem, it was determined that the Hagstrom-Hariharan condition was most accurate, the Bayliss-Turkel condition was least sensitive to changes in grid, and Bayliss-Turkel was best in terms of both accuracy and efficiency.

\begin{tabular}{|c|c|c|}
\hline $\begin{array}{l}\text { 14. SUBJECT TERMS } \\
\text { Boundary conditions; Ae } \\
\text { Unsteady aerodynamics; }\end{array}$ & $\begin{array}{l}\text { acoustics; Acoustic radiation; } \\
\text { usts }\end{array}$ & nputational fluid dynamics: \\
\hline $\begin{array}{l}\text { 17. SECURITY CLASSIFICATION } \\
\text { OF REPORT } \\
\text { Unclassified }\end{array}$ & $\begin{array}{l}\text { 18. SECURITY CLASSIFICATION } \\
\text { OF THIS PAGE } \\
\text { Unclassified }\end{array}$ & $\begin{array}{l}\text { 19. SECURITY CLASSIFICATION } \\
\text { OF ABSTRACT } \\
\text { Unclassified }\end{array}$ \\
\hline
\end{tabular}

